\title{
Expression and localization of vascular endothelial growth factor A (VEGFA) and its two receptors (VEGFR1/FLT1 and VEGFR2/FLK1/KDR) in the canine corpus luteum and utero-placental compartments during pregnancy and at normal and induced parturition
}

\author{
Gram, Aykut ; Hoffmann, Bernd ; Boos, Alois ; Kowalewski, Mariusz Pawel
}

\begin{abstract}
VEGFA is one of the most potent known inducers of angiogenesis. However, the function of angiogenic factors in the canine corpus luteum (CL) of pregnancy and in the pregnant uterus and placenta has not yet been elucidated. Therefore, here we investigated the expression and localization of VEGFA and its receptors (VEGFR1/FLT1 and VEGFR2/FLK1/KDR) in the canine CL and utero-placental compartments (ut-pl) throughout pregnancy until prepartum luteolysis. Antigestagen-mediated effects on expression of VEGF system in ut-pl were elucidated in mid-pregnant dogs. While displaying high individual variation, the luteal VEGFA was elevated during pre-implantation and post-implantation, followed by a decrease during mid-gestation, which was more pronounced at the mRNA level, and showed constant expression afterwards. Within the uterus, it increased following implantation and during mid-gestation in ut-pl compartments, but was downregulated at prepartum luteolysis. Luteal VEGFR1 expression resembled that of VEGFA; VEGFR2 remained unaffected throughout pregnancy. In ut-pl compartments, both receptors increased gradually towards mid-gestation; a prepartum decrease was observed for VEGFR1. Antigestagen-treatment resulted in decreased expression of ut-pl VEGFR1. In the CL, VEGFA stained in luteal cells. Uterine signals of VEGFA and its two receptors were observed in epithelial and vascular compartments, and in myometrium. In placental labyrinth, additionally, trophoblast stained positively. Luteal VEGFR1 was localized to the luteal cells and tunica media of blood vessels, whereas VEGFR2 stained only in capillary endothelial cells. The upregulation of luteal and the ut-pl VEGF system during early gestational stages supports the increased vascularization rate during this time. The diminishing effects of the prepartum endocrine milieu on VEGFA function seem to be more pronounced in the ut-pl units.
\end{abstract}

DOI: https://doi.org/10.1016/j.ygcen.2015.09.020

Posted at the Zurich Open Repository and Archive, University of Zurich

ZORA URL: https://doi.org/10.5167/uzh-117226

Journal Article

Accepted Version

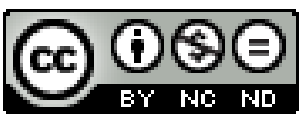

The following work is licensed under a Creative Commons: Attribution-NonCommercial-NoDerivatives 4.0 International (CC BY-NC-ND 4.0) License.

Originally published at: 
Gram, Aykut; Hoffmann, Bernd; Boos, Alois; Kowalewski, Mariusz Pawel (2015). Expression and localization of vascular endothelial growth factor A (VEGFA) and its two receptors (VEGFR1/FLT1 and VEGFR2/FLK1/KDR) in the canine corpus luteum and utero-placental compartments during pregnancy and at normal and induced parturition. General and Comparative Endocrinology, 223(1):54-65.

DOI: https://doi.org/10.1016/j.ygcen.2015.09.020 

Title: Expression and localization of vascular endothelial growth factor A (VEGFA) and its

2 two receptors (VEGFR1/FLT1 and VEGFR2/FLK1/KDR) in the canine corpus luteum and utero-placental compartments during pregnancy and at normal and induced parturition.

4

5 Authors: Aykut Gram ${ }^{1}$, Bernd Hoffmann ${ }^{2}$, Alois Boos ${ }^{1}$, Mariusz P Kowalewski ${ }^{1}$

6

$7{ }^{1}$ Institute of Veterinary Anatomy, Vetsuisse Faculty, University of Zurich, CH-8057 Zurich,

8 Switzerland.

$9 \quad{ }^{2}$ Clinic for Obstetrics, Gynecology and Andrology of Large- and Small Animals, Justus-Liebig

10 University Giessen, DE-35392 Giessen, Germany.

14 Correspondence:

15 Prof. Dr. Mariusz P. Kowalewski

16 Institute of Veterinary Anatomy

17 Vetsuisse Faculty

18 University of Zurich

19 Winterthurerstrasse 260

20 CH-8057 Zurich, Switzerland

21 Tel.: 0041-44-6358784; Fax.: 0041-44-6358943

22 Email: kowalewskipl@yahoo.de or kowalewski@vetanat.uzh.ch 


\section{Abstract}

25 VEGFA is one of the most potent known inducers of angiogenesis. However, the function of

26 angiogenic factors in the canine corpus luteum (CL) of pregnancy and in the pregnant uterus and

27 placenta has not yet been elucidated. Therefore, here we investigated the expression and 28 localization of VEGFA and its receptors (VEGFR1/FLT1 and VEGFR2/FLK1/KDR) in the

29 canine $\mathrm{CL}$ and utero-placental compartments (ut-pl) throughout pregnancy until prepartum

30 luteolysis. Antigestagen-mediated effects on expression of VEGF system in ut-pl were elucidated

31 in mid-pregnant dogs. While displaying high individual variation, the luteal VEGFA was

32 elevated during pre-implantation and post-implantation, followed by a decrease during mid-

33 gestation, which was more pronounced at the mRNA level, and showed constant expression

34 afterwards. Within the uterus, it increased following implantation and during mid-gestation in ut-

35 pl compartments, but was downregulated at prepartum luteolysis. Luteal VEGFR1 expression

36 resembled that of VEGFA; VEGFR2 remained unaffected throughout pregnancy. In ut-pl

37 compartments, both receptors increased gradually towards mid-gestation; a prepartum decrease

38 was observed for VEGFR1. Antigestagen-treatment resulted in decreased expression of ut-pl

39 VEGFR1. In the CL, VEGFA stained in luteal cells. Uterine signals of VEGFA and its two

40 receptors were observed in epithelial and vascular compartments, and in myometrium. In

41 placental labyrinth, additionally, trophoblast stained positively. Luteal VEGFR1 was localized to

42 the luteal cells and tunica media of blood vessels, whereas VEGFR2 stained only in capillary

43 endothelial cells. The upregulation of luteal and the ut-pl VEGF system during early gestational

44 stages supports the increased vascularization rate during this time. The diminishing effects of the

45 prepartum endocrine milieu on VEGFA function seem to be more pronounced in the ut-pl units.

46 Key words: domestic dog, corpus luteum (CL), uterus-placenta complex (ut-pl), angiogenesis, 


\section{Introduction}

49 In the reproductive tract, angiogenesis is an essential biological process involved in

50 decidualization, implantation and placentation, as well as corpus luteum (CL) formation. It is

51 regulated by the orchestration of diverse factors such as prostaglandins (PGs) and growth factors

52 (Fraser and Wulff, 2003; Reynolds et al., 2000; Sherer and Abulafia, 2001). Among these,

53 vascular endothelial growth factor (VEGF) is one of the most potent angiogenic agents (Ferrara

54 and Davis-Smyth, 1997). By acting through its two tyrosine kinase receptors, VEGFR1 (FLT1)

55 and VEGFR2 (FLK1/KDR), VEGF modulates migration and proliferation of endothelial cells

56 and also induces vascular permeability (Cebe-Suarez et al., 2006; Stuttfeld and Ballmer-Hofer,

57 2009).

58 The luteal expression and/or tissue concentration of VEGF is tightly correlated with development

59 of the CL as shown, e.g., in primates, including humans, and cattle (Berisha et al., 2000;

60 Ravindranath et al., 1992; Yamamoto et al., 1997). Its highest levels in growing CL correspond to

61 the high rate of proliferation and vascularization. As clearly shown in rats and mice, interfering

62 with the biological activity of VEGF at the level of its receptors, either VEGFR1 or VEGFR2,

63 results in impaired formation and function of the CL by preventing angiogenesis (Ferrara, 1998;

64 Zimmermann et al., 2001). Interestingly, however, no effects on preexisting vasculature were

65 seen, indicating the importance of the VEGF system primarily for neo-angiogenesis (Beck and

66 D'Amore, 1997). Furthermore, by interacting with angiopoietins, e.g., Ang1, VEGF supports

67 integrity of blood vessels and maintains their stability (Hanahan, 1997; Hazzard and Stouffer,

68 2000). Being itself a luteotropic factor, VEGF responds positively to LH in luteinizing granulosa

69 cells and the developing CL, and its expression is also triggered by hypoxia (Christenson and

70 Stouffer, 1997; Nishimura, 2010). 
71 Less information is available concerning the expression and function of the VEGF system in the

72 canine CL. Most of the knowledge relates to non-pregnant cyclic animals. Thus, VEGFA 73 expression is increased during the early luteal phase, and decreases by mid-diestrus (Mariani et 74 al., 2006). The decreased proliferative activity observed during the second half of diestrus is 75 associated with reduced density of the vascular network, as concluded from the lower expression 76 of endothelial cell-bound expression of endoglin (Hoffmann et al., 2004a; Papa and Hoffmann, 77 2011). The decreased vascularization rate does not change significantly afterwards, until the end 78 of the luteal life span (Hoffmann et al., 2004a), indicating that the diminished blood supply is not 79 the major factor responsible for the slowly progressing luteal regression in non-pregnant dogs 80 (Hoffmann et al., 2004b). In accordance with this, only recently unaltered levels of luteal 81 transcripts encoding for the VEGF system were shown during normal and induced prepartum 82 luteolysis/abortion (Kowalewski, 2014). The initially increased expression of vasculogenic 83 factors is accompanied by elevated luteal expression of transcripts encoding for hypoxia84 inducible factor $1 \alpha(\mathrm{HIF} 1 \alpha)$ and fibroblast growth factor 2 (FGF2) in the early CL from non85 pregnant bitches (Papa et al., 2014).

86 In the uterus, proper endometrial angiogenesis and vascular permeability are important for the 87 successful onset of pregnancy (Sherer and Abulafia, 2001). VEGF is involved in these processes 88 by coordinating the biochemical and functional changes associated with estrogen-dependent 89 uterine edema, vascular permeability and remodeling (Cullinan-Bove and Koos, 1993; Rockwell 90 et al., 2002; Shifren et al., 1996). High levels of uterine VEGF during early peri-implantation 91 stages of pregnancy were found in several species, e.g., rabbit, hamster, rat, mouse and human 92 (Das et al., 1997; Douglas et al., 2009; Rabbani and Rogers, 2001; Sugino et al., 2002; Yi et al., 93 1999). Similarly, in the dog, increased uterine levels of transcripts encoding for VEGFA and its 
94 receptors were found in response to free-floating, pre-implantation embryos (Bukowska et al.,

95 2011; Schafer-Somi et al., 2013). The localization and spatio-temporal expression of these factors

96 within the canine uterus and placenta, however, have not yet been established. Blockage of

97 VEGF in rats resulted in markedly decreased endometrial estrogen-induced microvascular 98 permeability (Rockwell et al., 2002). Following implantation, an inadequate vascular supply may

99 result in preeclampsia, fetal growth restriction or death (Barut et al., 2010; Cerdeira and

100 Karumanchi, 2012; Jarvenpaa et al., 2007), and VEGF is among the most important factors

101 involved in regulating placental angiogenesis (Reynolds and Redmer, 2001). Accordingly, in

102 mice, knockout of either of the VEGF receptors, i.e., VEGFR1 and/or VEGFR2, results in

103 multiple vascular malformations and consequently in embryonic lethality (Fong et al., 1995;

104 Shalaby et al., 1995). Across species, e.g, in humans, sheep and pigs, the placental localization of

105 VEGF is targeted to fetal trophoblast cells, showing a pregnancy stage-dependent expression

106 pattern (Bogic et al., 2001; Demir et al., 2004; Kimberly, 2001; Winther et al., 1999).

107 Taking into consideration the essential role of the VEGF system during the establishment and 108 maintenance of pregnancy, this study for the first time thoroughly describes the expression and

109 localization patterns of VEGFA, VEGFR1 and VEGFR2 in canine CL of pregnancy, as well as in 110 utero-placental compartments collected from dogs at selected stages throughout pregnancy.

111 Additionally, in order to investigate possible functional interplay between the VEGF system and 112 progesterone receptor (PGR) signaling at the utero-placental level, the expression of target genes 113 was assessed during antigestagen-induced abortion in mid-pregnant dogs. 


\section{Materials and Methods}

\section{$119 \quad 2.1$ Tissue collection and preservation}

120 Tissue material utilized for the present study was collected by ovariohysterectomy (OHE) from

121 healthy, mixed breed dogs at selected time points during pregnancy. The day of mating was 122 designated as day 0 of gestation for all bitches and was 2-3 days after ovulation. The time of 123 ovulation was detected by measuring plasma progesterone levels ( $>5 \mathrm{ng} / \mathrm{ml}$ in peripheral blood)

124 at 2-3 day intervals and by vaginal cytology. The tissue samples were classified as: pre-

125 implantation (days 8-12, $\mathrm{n}=5$ ), post-implantation (days 18-25, $\mathrm{n}=5$ ), mid-gestation (days 35-40,

$126 \mathrm{n}=5)$ and prepartum luteolysis $(\mathrm{n}=3)$. The pre-implantation stage of pregnancy was detected by 127 uterine flushing and recovery of pre-implantation, free-floating embryos under a

128 stereomicroscope. According to the descriptions by Amoroso (Amoroso, 1952) and Kehrer

129 (Kehrer, 1973), during the post-implantation stage of canine pregnancy the utero-placental 130 compartments are being formed, whereas at mid-gestation fully developed utero-placental 131 compartments are observed. The prepartum luteolysis was ascertained by regular measurements 132 of circulating $\mathrm{P} 4$ at $6 \mathrm{~h}$ intervals from day 58 of gestation onwards, until a marked decrease of P4 133 was observed in three consecutive measurements, eventually reaching levels below $3 \mathrm{ng} / \mathrm{ml}$, when 134 OHE was performed. In addition, abortions were induced by administering Aglepristone 135 (Alizine $^{\circledR}$, Virbac, Bad Oldesloe, Germany; 10mg/Kg bw, 2x/24 h apart) to mid-pregnant bitches 136 (days 40-45 of pregnancy, $n=10)$. Tissue samples were collected either $24 \mathrm{~h}(\mathrm{n}=5)$ or $72 \mathrm{~h}(\mathrm{n}=5)$

137 after the second treatment. All experimental procedures were performed according to the 138 guidelines of animal welfare legislation and approved by the respective authorities of Justus139 Liebig University in Giessen, Germany (permit no. II 25.3-19c20-15c GI 18/14 and VIG3-19c- 
140 20/15c GI 18,14), and the ethics committee University of Ankara (permit no. Ankara 2006/06),

141 Ankara, Turkey.

142 The tissue samples collected comprised: Corpora lutea (CL) and uterine samples (from the pre-

143 implantation stage of pregnancy), or utero-placental compartments (ut-pl), representing the full

144 thickness, middle part of the girdle, avoiding the marginal hematoma when derived from later

145 stages of pregnancy following implantation and/or following Aglepristone treatment.

146 Immediately after sampling and removal of excess connective tissue, samples were washed with

147 phosphate-buffered saline (PBS) and processed as described before (Gram et al., 2013;

148 Kowalewski et al., 2010; Kowalewski et al., 2011). Briefly: for immunohistochemistry (IHC),

149 tissues were fixed with $10 \%$ neutral PBS-buffered formalin for $24 \mathrm{~h}$ at $+4^{\circ} \mathrm{C}$, followed by washing

150 in PBS for one week and embedded in paraffin wax; for total RNA isolation, samples were

151 incubated in RNAlater ${ }^{\circledR}$ (Ambion Biotechnology $\mathrm{GmbH}$, Wiesbaden, Germany) for $24 \mathrm{~h}$ at $+4^{\circ} \mathrm{C}$

152 and then stored at $-80^{\circ} \mathrm{C}$ until analysis.

\section{$154 \quad 2.2$ Immunohistochemistry}

155 Immunohistochemical staining was performed using our previously described standard

156 immunoperoxidase method (Kowalewski et al., 2006a; Kowalewski et al., 2006b). Briefly,

157 formalin-fixed paraffin-embedded tissue sections $\left(2-3 \mu \mathrm{m}\right.$ thick) were placed on Super Frost ${ }^{\circledR}$

158 microscope slides (Menzel-Glaeser, Braunschweig, Germany); xylene was used for

159 deparaffinization, then a graded ethanol series was applied for rehydration. After subsequent

160 washing under tap water, epitope retrieval was performed in a microwave oven at $560 \mathrm{~W}$ for 15

$161 \mathrm{~min}$ in $10 \mathrm{mM}$ citrate buffer $\mathrm{pH}$ 6.0. For VEGFA and VEGFR1 localization in luteal samples,

162 enzymatic digestion was performed with 0.25\% pepsin (Sigma-Aldrich Chemie GmbH, Buchs,

163 Switzerland) in $10 \mathrm{mM} \mathrm{HCl}$ for $10 \mathrm{~min}$ at $37^{\circ} \mathrm{C}$, instead of heat-induced antigen retrieval. 
164 Endogenous peroxidase activity blocking was done by treating slides with $0.3 \%$ hydrogen

165 peroxide in methanol. In order to reduce background staining, sections were incubated with either

$16610 \%$ normal goat serum or $10 \%$ normal horse serum, depending on the source species of the

167 secondary antibody. They were then incubated overnight at $+4{ }^{\circ} \mathrm{C}$ with mouse monoclonal anti-

168 VEGF (ab68334; for ut-pl tissue sections diluted 1:100, for luteal samples 1:300) purchased from

169 Abcam, Cambridge, UK. Rabbit affinity-purified polyclonal anti-VEGFR1/Flt-1 (sc-316; for ut-

170 pl tissue sections diluted 1:300, for luteal samples 1:350) was purchased from Santa Cruz

171 Biotechnology Inc., CA, USA, and rabbit monoclonal anti-VEGFR2/KDR/Flk-1 (2479S; for ut-

172 pl tissue sections the dilution was 1:50, for luteal samples 1:300) from Cell Signaling Technology

173 Inc., Danvers, MA, USA. Negative controls consisted of samples omitting the primary antibody,

174 and non-immunized IgG of the same species instead of primary antibody used at the same

175 dilution and protein concentration as the primary antibody (the so-called isotype control).

176 This was followed by incubation with biotin-labeled secondary antibody incubation at a 1:100

177 dilution. The following secondary antibodies were used for $30 \mathrm{~min}$ : biotinylated goat anti-rabbit

178 IgG BA-1000 and horse anti-mouse IgG BA-2000 (both from Vector Laboratories Inc.,

179 Burlingame, CA, USA). For amplification of signals, the streptavidin-peroxidase Vectastain ABC

180 kit (Vector Laboratories, Inc.) was added to sections for $30 \mathrm{~min}$, and finally they were treated

181 with the Liquid DAB+ substrate kit (Dako Schweiz AG, Baar, Switzerland) to visualize peroxide 182 activity. Slides were counterstained with hematoxylin, dehydrated in a graded ethanol series, 183 equilibrated in xylene, and mounted in Histokit (Assistant, Osterode, Germany).

\section{$185 \quad$ 2.3 Total RNA isolation and Real Time (TaqMan) PCR}

186 Total RNA was extracted from tissue samples with TRIzol® reagent (Invitrogen, Carlsbad, CA, 187 USA) according to the manufacturer's instructions. Concentrations of RNA were examined with 
188 a NanoDrop 2000C ${ }^{\circledR}$ spectrophotometer (Thermo Fisher Scientific AG, Reinach, Switzerland).

189 Afterwards, samples were DNAse-treated with RQ1 RNase-free DNase (Promega, Dübendorf,

190 Switzerland) and reverse transcribed (RT reaction) following our previously published protocol

191 and utilizing random hexamers as primers and other reagents from Applied Biosystems by

192 Thermo Fisher Scientific, Foster City, CA, USA (Kowalewski et al., 2011; Kowalewski et al.,

193 2006b). Semi-quantitative real time (TaqMan) PCR reaction was performed in an automated

194 fluorometer (ABI PRISM 7500 Sequence Detection System from Applied Biosystems by Thermo

195 Fisher Scientific). The primers and probes used in the PCR reaction were designed using Primer

196 Express software version 2.0 (Applied Biosystems by Thermo Fisher Scientific) and were

197 purchased from Microsynth, Balgach, Switzerland. Selected amplicons of each gene were sent for

198 commercial sequencing (Microsynth). The list of primers, 6-carboxyfluorescein (6-FAM) and 6-

199 carboxytetramethylrhodamine (TAMRA)-labelled TaqMan probes, and the length of PCR

200 products are presented in Table 1. Autoclaved water and the so-called RT-minus controls

201 (samples that were not reverse-transcribed) served as negative controls. Each reaction mixture

202 comprised: 200nM TaqMan Probe, $300 \mathrm{nM}$ of each primer, $12.5 \mu$ l Fast Start Universal Probe

203 Master $(\mathrm{ROX})^{\circledR}$ (Roche Diagnostics, Mannheim, Germany) and $5 \mu$ cDNA corresponding to

204 100ng total RNA per sample. The amplification conditions were as follows: denaturation at $95^{\circ} \mathrm{C}$

205 for $10 \mathrm{~min}, 40$ cycles at $95^{\circ} \mathrm{C}$ for $15 \mathrm{sec}$ and 1 cycle at $60^{\circ} \mathrm{C}$ for $60 \mathrm{sec}$. The efficiency of each

206 target gene was calculated using the CT slope method, ensuring approximately $100 \%$ reaction

207 efficiency, and quantification was performed using a comparative CT method ( $\Delta \Delta \mathrm{CT}$ method)

208 according to the manufacturer's protocols for the ABI PRISM ${ }^{\circledR} 7500$ Sequence Detection

209 System (Applied Biosystems) and as described previously (Kowalewski et al., 2011; Kowalewski

210 et al., 2006b). The sample with the lowest concentration of the target gene served as the 
211 calibrator in the $\Delta \Delta \mathrm{CT}$ method. Three reference genes were used for normalizing the results:

212 GAPDH, 18SrRNA (Table 1), and cyclophilin. A commercially available gene-specific TaqMan ${ }^{\circledR}$

213 system of canine-specific cyclophilin A was purchased from Applied Biosystems by Thermo

214 Fisher Scientific (Prod. No. Cf03986523_gH).

215 Due to the uneven distribution of data, logarithmic transformation was performed for

216 normalization of the data and the geometric means $(\mathrm{Xg}) \pm$ deviation factors were calculated for

217 the analysis of target gene expression. The effects of the observational group on target gene

218 mRNA levels were assessed by applying a parametric one-way analysis of variance (ANOVA).

219 In cases of $\mathrm{P}<0.05$, multiple comparisons tests were applied: the Tukey-Kramer multiple

220 comparisons test in experiments showing temporal changes in gene expression during the course

221 of pregnancy, and Dunnett's multiple comparisons test in experiments showing the expression of

222 target genes after Aglepristone-induced luteolysis. In the latter experiments, the results present

223 the n-fold change in gene expression compared to its mRNA-levels in ut-pl collected at mid-

224 gestation. All tests were performed using the statistical software program GraphPad 3.06

225 (GraphPad Software, San Diego, CA, USA).

227 3. Results

$228 \quad 3.1$ Time-dependent expression of the VEGF-system in canine CL and ut-pl compartments

229 throughout pregnancy.

230 The expression of mRNA encoding for VEGFA and its two receptors (VEGFR1 and VEGFR2)

231 was detectable in all tissue samples investigated. While the luteal VEGFA and VEGFR1 were

232 significantly modulated over time $(\mathrm{P}=0.01$ and $\mathrm{P}<0.001$, respectively) (Fig. $1 \mathrm{~A}, \mathrm{~B})$, the expression

233 of VEGFR2 did not change significantly $(\mathrm{P}=0.31)$ (Fig. 1C). VEGFA was elevated at the 
234 beginning of the luteal phase with highest values noted post-implantation. This was followed by a

235 significant decrease at mid-gestation $(\mathrm{P}<0.05)$ with no further changes later on, during prepartum

236 luteolysis (Fig. 1A). A similar expression pattern was observed for luteal VEGFR1 mRNA levels,

237 which were strongly increased post-implantation and significantly lower afterwards, at mid-term

238 and during prepartum luteolysis $(\mathrm{P}<0.001)$ (Fig. 1B).

239 The expression of all three target genes, i.e., VEGFA, VEGFR1 and VEGFR2, in ut-pl

240 compartments was time-dependent $(\mathrm{P}=0.002, \mathrm{P}=0.005$ and $\mathrm{P}=0.001$, respectively) (Fig. 2A-C).

241 Implantation and placentation were associated with gradually increasing expression of these

242 target genes towards mid-gestation, showing, however, large individual variations among groups

243 and individuals. This increase was strongest for VEGFR2 mRNA, which was already

244 significantly unpregulated in ut-pl after implantation $(\mathrm{P}<0.01)$, and further markedly elevated at

245 mid-gestation $(\mathrm{P}<0.001)$ when compared with pre-implantation (Fig. 2C). The prepartum

246 luteolysis was characterized by significantly decreasing levels of VEGF and VEGFR1 $(\mathrm{P}<0.001$

247 and $\mathrm{P}<0.01$, respectively) (Fig. 2A,B), while VEGFR2 levels remained unaffected (Fig. 2C).

249 3.2 The effect of antigestagen treatment on expression of the VEGF system in ut-pl 250 compartments.

251 The effect of applying the antigestagen Aglepristone ${ }^{\circledR}$ on expression of the VEGF system in ut-pl

252 compartments was assessed in mid-pregnant dogs. Non-treated mid-pregnant dogs served as

253 controls. Although displaying high individual variation, the expression of VEGFA and VEGFR2

254 did not change significantly $(\mathrm{P}=0.75$ and $\mathrm{P}=0.32$, respectively) (Fig. 2D,F), while VEGFR1

255 mRNA levels were significantly affected $(\mathrm{P}=0.006)$ and had already decreased $24 \mathrm{~h}$ after the

256 second treatment $(\mathrm{P}<0.01)$, remaining suppressed at $72 \mathrm{~h}$ ( $\mathrm{P}<0.01$ compared with controls) (Fig.

257 2E). 
259 3.3 Immunohistochemical detection of the VEGF system throughout pregnancy

260 IHC was applied for detection of VEGFA, VEGFR1 and VEGR2 expression in canine CL and ut-

261 pl compartments during pregnancy. In CL, VEGFA was localized predominantly in luteal cells, 262 with only weak staining in non-steroidogenic luteal compartments of the CL. While characterized

263 by high individual variations, the signals appeared stronger at post-implantation and mid264 gestation stages of pregnancy. Much weaker staining was observed at pre-implantation stage, and

265 only weak or no signals could be detected during prepartum luteolysis (Fig. 3A-D). VEGFR1

266 expression was localized to the luteal cells and tunica media of blood vessels throughout

267 pregnancy (Fig 4A-D). At the time of prepartum luteolysis, luteal cells seemed to stain more 268 weakly, while signals in the tunica media of vessels were still clearly visible (Fig 4D). As for 269 VEGFR2, it was localized in luteal blood vessels with distinctly stronger signals in endothelial 270 cells of capillaries and weaker staining in the tunica media of some larger vessels (Fig 5A-D).

271 The staining did not vary widely throughout pregnancy. Luteal cells showed weaker or no 272 immunoreactions for VEGFR2 from pre-implantation until prepartum luteolysis.

273 Prior to implantation, uterine VEGFA signals were localized to the endometrial luminal surface 274 epithelial cells, as well as in superficial and deep uterine glands and myometrium (Fig 6A,B).

275 Deep uterine glands stained more weakly than superficial ones (Fig. 6B). Weaker stromal signals 276 were localized predominantly in vascular endothelial cells (Fig. 6A,B). Following implantation, a 277 similar uterine cellular localization pattern was observed for VEGFA signals in the uterine part of 278 the ut-pl compartments (Fig 6C,D and 6F,G). However, endometrial and myometrial signals 279 appeared to be weaker during prepartum luteolysis (Fig 6F,G). In the placental labyrinth, VEGFA 280 signal intensities increased towards mid-gestation, resulting in strong staining in fetal trophoblast 281 cells (predominantly cytotrophoblast), and in vascular endothelial cells both in the placenta 
282 materna and fetalis; in contrast, only weak or no signals were observed in maternal stroma-

283 derived decidual cells (Fig 6E and 6H). Signal intensities were weaker during prepartum

284 luteolysis (Fig 6H).

285 The uterine expression of VEGFR1 was localized in superficial and deep uterine glands and 286 myometrium prior to implantation (Fig 7A,B). No or negligible immunostaining was seen in 287 luminal epithelial cells of the endometrial surface (Fig 7A). As for VEGF, some stromal signals 288 were visible in the vascular bed. Implantation was associated with strong staining, especially in 289 the placental parts of the ut-pl units (Fig 7C,D). The pattern of uterine VEGFR1 expression 290 remained constant with, however, only moderate signal intensity (Fig 7C,D and Fig 7F,G ).

291 Within the placental labyrinth, strong signals were seen in vascular endothelial cells and in 292 cytotrophoblast cells, whereas only weak signals were localized in syncytiotrophoblast cells and 293 maternal decidual cells (Fig 7E). During prepartum luteolysis, signals appeared weaker with,

294 however, a localization pattern similar to that during earlier stages of pregnancy (Fig 7H). With 295 regard to VEGFR2, its expression in the early pregnant pre-implantation uterus matched the 296 localization pattern of VEGFA with signals localized in luminal surface epithelial cells and 297 superficial and deep uterine glands. Stronger immunoreactions were observed in capillary 298 pericytes, vascular endothelial cells and myometrium (Fig 8A,B). Similar endometrial and 299 myometrial signals were found following implantation and placentation (Fig. 8C,D and 8F,G); 300 the superficial glandular epithelial cells (part of the so-called glandular chambers), myometrium 301 and vascular endothelial cells stained positively. Placental localization of VEGFR2 was detected 302 in fetal trophoblast cells, which appeared to be predominantly cytotrophoblasts, and in vascular 303 endothelial cells of the placenta materna and fetalis (Fig 8E). At prepartum luteolysis, the 304 maternal endothelial cells especially stained strongly for VEGFR2. Only weak staining was 305 noticed for VEGFR2 in maternal decidual cells (Fig 8E and 8H). 


\section{4. Discussion}

308 The establishment and maintenance of pregnancy strongly depend on the appropriate functioning 309 of luteal, uterine and placental vasculogenic and angiogenic activities, and the VEGF system is a 310 set of master regulators controlling these activities. In the present study, we investigated its

311 spatio-temporal expression in the dog at selected time points during pregnancy, i.e., pre-

312 implantation, post-implantation, mid-gestation, and during prepartum luteolysis.

313 The early luteal phase was characterized by elevated expression of the VEGF system in canine

314 pregnant CL, consistent with similar findings described in other species, e.g., humans, cattle, pigs

315 and sheep (Berisha et al., 2000; Kamat et al., 1995; Redmer et al., 1996; Yamamoto et al., 1997).

316 The expression of transcripts encoding for VEGFA and its VEGFR1 receptor decreased by the 317 mid-luteal phase and did not change until prepartum luteolysis. These findings are in accordance 318 with the expression pattern of the VEGF system observed in the CL of non-pregnant cyclic dogs

319 until late luteal regression (Mariani et al., 2006). Although individual variations were wide, the 320 profiles of the respective protein expression of both factors, i.e., VEGFA and VEGFR1, seemed

321 less dramatic, and showed a strong depression first appearing at prepartum luteolysis. This 322 indicates a possible divergence between the mechanisms regulating their mRNA expression and

323 the protein turnover rates during the regression of canine CL. Taking into account the similar P4

324 profiles observed in dogs regardless of their reproductive status, i.e., in pregnant and non325 pregnant bitches, and the postulated initial transient period of gonadotropic independency, this

326 further emphasizes the involvement of inherent regulatory mechanisms controlling canine CL 327 function.

328 Thus, as expected, VEGFA appears to be an essential angiogenic factor during canine CL 329 formation. Furthermore, a functional interplay between the different cellular components in the 
330 canine CL is strongly implied from the distribution pattern of the VEGF system within the CL.

331 Thus, whereas in our study, VEGFA was expressed virtually exclusively in the luteal cells, its

332 receptor VEGFR1 was localized at both locations, i.e., in steroidogenic cells and in luteal blood

333 vessels. Moreover, VEGFR2 was co-localized with VEGFR1 in the luteal vascular components.

334 This, indeed, strongly suggests both autocrine and paracrine functions of VEGFA and its

335 receptors within an autoregulatory feedback loop in the canine CL. As for the possible regulatory

336 factors modulating VEGFA expression, the hypoxia-sensitive HIF1 $\alpha$ might be involved, as its

337 expression is clearly detectable during the developmental period of canine CL (Papa et al., 2013).

338 Moreover, PGE2 was shown to be a positive regulator of VEGF expression in swine luteal cells

339 in vitro (Kowalczyk et al., 2008). Similarly, in rodents, blocking cyclooxygenase 2

340 (COX2/PTGS2) in the newly formed CL, using the selective COX2 blocker NS-398, decreased

341 not only the steroidogenic luteal capacity and, thereby, serum levels of P4, but also the density of

342 luteal capillary vessels (Sakurai et al., 2005). In line with this, PGE2 is also an important

343 regulator of CL function in dogs during its early development (Kowalewski et al., 2013;

344 Kowalewski et al., 2015). This was clearly shown recently by applying the selective COX2

345 blocker firocoxib to non-pregnant dogs during early diestrus, which resulted in strong

346 suppression of intraluteal PGE2 synthesis and decreased expression of steroidogenic acute

347 regulatory (STAR) protein (Kowalewski et al., 2015). The possible interplay between these two

348 functional systems, i.e., PGs and VEGF system, in regulating STAR expression and luteal P4

349 output remains to be elucidated in the dog. This is particularly interesting since the steroidogenic

350 potential of VEGF has been implicated also in the cow, where antibody-mediated blocking of

351 VEGF function resulted in suppressed luteal STAR mRNA expression and significantly reduced

352 steroidogenic output (Yamashita et al., 2008). 
353 As for the ut-pl compartments, the expression of VEGFA and its receptors increased following

354 implantation, appearing to be associated with placental development, as indicated by the strong

355 expression of all factors in the fetal parts of the placenta.

356 At the pre-implantation stage, VEGFA was localized in capillaries and epithelial uterine 357 components, implying a role of VEGFA in establishing the uterine edema and vascular 358 permeabilization needed for embryo attachment and implantation as described in other species 359 (Ancelin et al., 2002; Halder et al., 2000; Rockwell et al., 2002). Accordingly, studies conducted 360 in human and rat uterus showed that VEGF expression is induced by P4 and estrogens (Ancelin 361 et al., 2002; Cullinan-Bove and Koos, 1993; Hyder et al., 2000). This might be also true for dogs, 362 in which uterine P4- and estrogen- receptors (PGR, ER $\alpha$ and ER $\beta$ ) were colocalized with 363 VEGFA expression during the pre-implantation period (Kautz et al., 2014). Additional studies in 364 rodents established the interrelationship between VEGF activity and estrogen-induced uterine 365 decidualization and implantation (Rockwell et al., 2002). Moreover, VEGFR2-mediated 366 pathways were shown to be involved in regulation of cell differentiation during establishment of 367 pregnancy in mice (Douglas et al., 2009). Also in the dog, as presented herein, VEGFR2 368 expression was stronger than VEGFR1 in uterine and placental vascular beds, suggesting the 369 important role of this receptor in local VEGFA-dependent angiogenic effects.

370 Following placentation, endometrial signals for VEGF and its receptors were similar to those 371 observed in the pre-implantation uterus. However, strong placental signals were localized in fetal 372 trophoblast cells, suggesting that the VEGF system might play an autocrine and/or paracrine role 373 in placental angiogenesis, and in maintaining changes in utero-placental vascular permeability, 374 and thereby, in fetal and placental development. Our findings concerning the distribution pattern 375 of VEGF system in trophoblast cells are in agreement with similar studies performed in other 
376 species, e.g., human, sheep or rat (Ahmed et al., 1995; Bogic et al., 2001; Demir et al., 2004;

377 Watanabe, 1998). Whereas during prepartum luteolysis the expression of VEGFR2 remained

378 unaffected, the VEGFA and VEGFR1 were markedly suppressed. In the dog, interfering with P4

379 function by blocking its binding to PGR triggers the luteolytic cascade, resulting in the prepartum

380 PGF2 $\alpha$ increase (Kowalewski et al., 2010). Considering the placenta, this increase must originate

381 in trophoblast cells where COX2 is localized (Kowalewski et al., 2010). Recently, the potential of

382 canine placental and uterine homogenates to convert PGE2 to PGF2 $\alpha$ was shown (Gram et al.,

383 2014). In addition, the PGE2-generating enzyme, PTGES, was localized in the fetal trophoblast

384 and responded positively to the suppression of PGR function (Gram et al., 2014; Kowalewski et

385 al., 2010). In the present study, both VEGFA and VEGFR2 exhibited large individual variations

386 upon treatment with the antigestagen Aglepristone ${ }^{\circledR}$, contrasting with the strongly suppressed

387 expression of VEGFR1. The latter in particular can be seen as a sign of a functional change

388 within the trophoblast towards prepartum PG synthesis and induction of the luteolytic cascade.

389 Suppression of the VEGF system function during both normal and induced parturition/abortion

390 might be involved in facilitating placental detachment.

391 In conclusion, the VEGF system is actively modulated in canine CL and ut-pl compartments

392 throughout gestation. Whereas, at least at the mRNA level, its expression is strongly diminished

393 in mature, mid-term CL exhibiting a fully developed vascular bed, the strong placental

394 expression of VEGFA and both receptors suggests their involvement not only in placental

395 angiogenesis and vasculogenesis but also during maintenance of placental function, possibly by

396 supporting trophoblast differentiation and/or migration. 


\section{Acknowledgements:}

400 Authors are grateful to Prof. Dr. Selim Aslan, Near East University, Cyprus (formerly of the

401 University of Ankara, Turkey), and his team for provision of the tissue material, and to Dr. Barry

402 Bavister for careful editing of the manuscript. The technical expertise and contributions of

403 Elisabeth Högger and Stefanie Ihle are greatly appreciated.

404

405 Grant support: Swiss National Science Foundation (SNSF) research grant number 406 31003A_160251 to MPK.

407

408

409 Conflict of interest: The authors declare that there is no conflict of interest. All authors read and 410 approved the final version of the manuscript. 


\section{References:}

415 Ahmed, A., Li, X.F., Dunk, C., Whittle, M.J., Rushton, D.I., Rollason, T., 1995. Colocalisation of 416 vascular endothelial growth factor and its Flt-1 receptor in human placenta. Growth Factors 12, $417 \quad 235-243$.

418 Amoroso, E.C., 1952. Placentation. In: Parkers AS (ed.) Marshall`s physiology of reproduction. 419 Longmans Green, London. 127-316.

420 Ancelin, M., Buteau-Lozano, H., Meduri, G., Osborne-Pellegrin, M., Sordello, S., Plouet, J., Perrot-Applanat, M., 2002. A dynamic shift of VEGF isoforms with a transient and selective progesterone-induced expression of VEGF189 regulates angiogenesis and vascular permeability in human uterus. Proc Natl Acad Sci U S A 99, 6023-6028.

Barut, F., Barut, A., Gun, B.D., Kandemir, N.O., Harma, M.I., Harma, M., Aktunc, E., Ozdamar, S.O., 2010. Intrauterine growth restriction and placental angiogenesis. Diagn Pathol 5, 24.

Beck, L., Jr., D'Amore, P.A., 1997. Vascular development: cellular and molecular regulation. Faseb J 11, 365-373.

Berisha, B., Schams, D., Kosmann, M., Amselgruber, W., Einspanier, R., 2000. Expression and tissue concentration of vascular endothelial growth factor, its receptors, and localization in the bovine corpus luteum during estrous cycle and pregnancy. Biol Reprod 63, 1106-1114.

Bogic, L.V., Brace, R.A., Cheung, C.Y., 2001. Developmental expression of vascular endothelial growth factor (VEGF) receptors and VEGF binding in ovine placenta and fetal membranes. Placenta 22, 265-275.

Bukowska, D., Kempisty, B., Jackowska, M., Wozna, M., Antosik, P., Piotrowska, H., Jaskowski, J.M., 2011. Analysis of integrins and vascular endothelial growth factor isoforms mRNA expression in the canine uterus during perimplantation period. Pol J Vet Sci 14, 253-258. Cebe-Suarez, S., Zehnder-Fjallman, A., Ballmer-Hofer, K., 2006. The role of VEGF receptors in angiogenesis; complex partnerships. Cell Mol Life Sci 63, 601-615.

Cerdeira, A.S., Karumanchi, S.A., 2012. Angiogenic factors in preeclampsia and related disorders. Cold Spring Harb Perspect Med 2(11).

Christenson, L.K., Stouffer, R.L., 1997. Follicle-stimulating hormone and luteinizing hormone/chorionic gonadotropin stimulation of vascular endothelial growth factor production by macaque granulosa cells from pre- and periovulatory follicles. J Clin Endocrinol Metab 82, 21352142.

Cullinan-Bove, K., Koos, R.D., 1993. Vascular endothelial growth factor/vascular permeability factor expression in the rat uterus: rapid stimulation by estrogen correlates with estrogen-induced increases in uterine capillary permeability and growth. Endocrinology 133, 829-837.

Das, S.K., Chakraborty, I., Wang, J., Dey, S.K., Hoffman, L.H., 1997. Expression of vascular endothelial growth factor (VEGF) and VEGF-receptor messenger ribonucleic acids in the periimplantation rabbit uterus. Biol Reprod 56, 1390-1399.

Demir, R., Kayisli, U.A., Seval, Y., Celik-Ozenci, C., Korgun, E.T., Demir-Weusten, A.Y., Huppertz, B., 2004. Sequential expression of VEGF and its receptors in human placental villi during very early pregnancy: differences between placental vasculogenesis and angiogenesis. Placenta 25, 560-572.

Douglas, N.C., Tang, H., Gomez, R., Pytowski, B., Hicklin, D.J., Sauer, C.M., Kitajewski, J., Sauer, M.V., Zimmermann, R.C., 2009. Vascular endothelial growth factor receptor 2 (VEGFR2) functions to promote uterine decidual angiogenesis during early pregnancy in the mouse. Endocrinology 150, 3845-3854. 
Ferrara, N., Davis-Smyth, T., 1997. The biology of vascular endothelial growth factor. Endocr Rev 18, 4-25.

461 Ferrara, N.C., H. Davis-Symth,T. Gerberer,H. Nguyen,T.N. Chisholm,V. Hillan,K. Schwall,R., 1998. Vascular endothelial growth factor is essential for corpus luteum angiogenesis. Nature 4, 336-340.

Fong, G.H., Rossant, J., Gertsenstein, M., Breitman, M.L., 1995. Role of the Flt-1 receptor tyrosine kinase in regulating the assembly of vascular endothelium. Nature 376, 66-70.

Fraser, H.M., Wulff, C., 2003. Angiogenesis in the corpus luteum. Reprod Biol Endocrinol 1, 88. Gram, A., Buchler, U., Boos, A., Hoffmann, B., Kowalewski, M.P., 2013. Biosynthesis and degradation of canine placental prostaglandins: prepartum changes in expression and function of prostaglandin F2 $\alpha$-synthase (PGFS, AKR1C3) and 15-hydroxyprostaglandin dehydrogenase (HPGD). Biol Reprod 89(1):2.

Gram, A., Fox, B., Buchler, U., Boos, A., Hoffmann, B., Kowalewski, M.P., 2014. Canine placental prostaglandin E2 synthase: expression, localization, and biological functions in providing substrates for prepartum PGF2alpha synthesis. Biol Reprod 91(6):154.

Halder, J.B., Zhao, X., Soker, S., Paria, B.C., Klagsbrun, M., Das, S.K., Dey, S.K., 2000. Differential expression of VEGF isoforms and VEGF(164)-specific receptor neuropilin-1 in the mouse uterus suggests a role for $\operatorname{VEGF(164)~in~vascular~permeability~and~angiogenesis~during~}$ implantation. Genesis 26, 213-224.

Hanahan, D., 1997. Signaling vascular morphogenesis and maintenance. Science 277, 48-50.

Hazzard, T.M., Stouffer, R.L., 2000. Angiogenesis in ovarian follicular and luteal development. Baillieres Best Pract Res Clin Obstet Gynaecol 14, 883-900. Hoffmann, B., Busges, F., Baumgartner, W., 2004a. Immunohistochemical detection of CD4-, CD8- and MHC II-expressing immune cells and endoglin in the canine corpus luteum at different stages of dioestrus. Reprod Domest Anim 39, 391-395. luteum-function in the bitch. Reprod Domest Anim 39, 232-240.

Hyder, S.M., Huang, J.C., Nawaz, Z., Boettger-Tong, H., Makela, S., Chiappetta, C., Stancel, G.M., 2000. Regulation of vascular endothelial growth factor expression by estrogens and progestins. Environ Health Perspect 108 Suppl 5, 785-790.

Jarvenpaa, J., Vuoristo, J.T., Savolainen, E.R., Ukkola, O., Vaskivuo, T., Ryynanen, M., 2007. Altered expression of angiogenesis-related placental genes in pre-eclampsia associated with intrauterine growth restriction. Gynecol Endocrinol 23, 351-355.

Kamat, B.R., Brown, L.F., Manseau, E.J., Senger, D.R., Dvorak, H.F., 1995. Expression of vascular permeability factor/vascular endothelial growth factor by human granulosa and theca lutein cells. Role in corpus luteum development. Am J Pathol 146, 157-165.

Kautz, E., Gram, A., Aslan, S., Ay, S.S., Selcuk, M., Kanca, H., Koldas, E., Akal, E., Karakas, K., Findik, M., Boos, A., Kowalewski, M.P., 2014. Expression of genes involved in the embryomaternal interaction in the early pregnant canine uterus. Reproduction, 703-717.

Kehrer, A., 1973. [Chorionic development and structure of the placenta zonaria in the cat, dog and fox (author's transl)]. Z Anat Entwicklungsgesch 143, 25-42.

500 Kimberly, A.V.M., E.W. Stephan,P.F., 2001. Relationship Between Placental Vascular 501 Endothelial Growth Factor Expression and Placental/Endometrial Vascularity in the Pig. Biol 502 Reprod, 1821-1825.

503 Kowalczyk, A.E., Kaczmarek, M.M., Schams, D., Ziecik, A.J., 2008. Effect of prostaglandin E2 504 and tumor necrosis factor alpha on the VEGF-receptor system expression in cultured porcine 505 luteal cells. Mol Reprod Dev 75, 1558-1566. 
506

507

508

509

510

511

512

513

514

515

516

517

518

519

520

521

522

523

524

525

526

527

528

529

530

531

532

533

534

535

536

537

538

539

540

541

542

543

544

545

546

547

548

549

550

551

552
Kowalewski, M.P., 2014. Luteal regression vs. prepartum luteolysis: regulatory mechanisms governing canine corpus luteum function. Reprod Biol 14, 89-102.

Kowalewski, M.P., Beceriklisoy, H.B., Pfarrer, C., Aslan, S., Kindahl, H., Kucukaslan, I., Hoffmann, B., 2010. Canine placenta: a source of prepartal prostaglandins during normal and antiprogestin-induced parturition. Reproduction 139, 655-664.

Kowalewski, M.P., Fox, B., Gram, A., Boos, A., Reichler, I., 2013. Prostaglandin E2 functions as a luteotrophic factor in the dog. Reproduction 145, 213-226.

Kowalewski, M.P., Ihle, S., Siemieniuch, M.J., Gram, A., Boos, A., Zdunczyk, S., Fingerhut, J., Hoffmann, B., Schuler, G., Jurczak, A., Domoslawska, A., Janowski, T., 2015. Formation of the early canine CL and the role of prostaglandin E2 (PGE2) in regulation of its function: an in vivo approach. Theriogenology 83, 1038-1047.

Kowalewski, M.P., Mason, J.I., Howie, A.F., Morley, S.D., Schuler, G., Hoffmann, B., 2006 a. Characterization of the canine 3beta-hydroxysteroid dehydrogenase and its expression in the corpus luteum during diestrus. J Steroid Biochem Mol Biol 101, 254-262.

Kowalewski, M.P., Meyer, A., Hoffmann, B., Aslan, S., Boos, A., 2011. Expression and functional implications of peroxisome proliferator-activated receptor gamma (PPARgamma) in canine reproductive tissues during normal pregnancy and parturition and at antiprogestin induced abortion. Theriogenology 75, 877-886.

Kowalewski, M.P., Schuler, G., Taubert, A., Engel, E., Hoffmann, B., 2006b. Expression of cyclooxygenase 1 and 2 in the canine corpus luteum during diestrus. Theriogenology 66, 14231430.

Mariani, T.C., do Prado, C., Silva, L.G., Paarmann, F.A., Lima, M.C., Carvalho, I., Campos, D.B., Artoni, L.P., Hernandez-Blazquez, F.J., Papa, P.C., 2006. Immunohistochemical localization of VEGF and its receptors in the corpus luteum of the bitch during diestrus and anestrus. Theriogenology 66, 1715-1720.

Nishimura, R.O., K., 2010. Hypoxia is Important for Establishing Vascularization During Corpus Luteum Formation in Cattle. J Reprod Dev, 110-116.

Papa, P.C., Hoffmann, B., 2011. The corpus luteum of the dog: source and target of steroid hormones? Reprod Domest Anim 46, 750-756.

Papa, P.C., Sousa, L.M., Silva Rdos, S., de Fatima, L.A., da Fonseca, V.U., do Amaral, V.C., Hoffmann, B., Alves-Wagner, A.B., Machado, U.F., Kowalewski, M.P., 2013. Glucose transporter 1 expression accompanies hypoxia sensing in the cyclic canine corpus luteum. Reproduction 147, 81-89.

Papa, P,C., Sousa, L.M., Silva Rdos, S., de Fatima, L.A., da Fonseca, V.U., do Amaral, V.C., Hoffmann, B., Alves-Wagner, A.B., Machado, U.F., Kowalewski, M.P., 2014. Glucose transporter 1 expression accompanies hypoxia sensing in the cyclic canine corpus luteum. Reproduction 147, 81-89.

Rabbani, M.L., Rogers, P.A., 2001. Role of vascular endothelial growth factor in endometrial vascular events before implantation in rats. Reproduction 122, 85-90.

Ravindranath, N., Little-Ihrig, L., Phillips, H.S., Ferrara, N., Zeleznik, A.J., 1992. Vascular endothelial growth factor messenger ribonucleic acid expression in the primate ovary. Endocrinology 131, 254-260.

Redmer, D.A., Dai, Y., Li, J., Charnock-Jones, D.S., Smith, S.K., Reynolds, L.P., Moor, R.M., 1996. Characterization and expression of vascular endothelial growth factor (VEGF) in the ovine corpus luteum. J Reprod Fertil 108, 157-165.

Reynolds, L.P., Grazul-Bilska, A.T., Redmer, D.A., 2000. Angiogenesis in the corpus luteum. Endocrine 12, 1-9. 
553 Reynolds, L.P., Redmer, D.A., 2001. Angiogenesis in the placenta. Biol Reprod 64, 1033-1040.

554 Rockwell, L.C., Pillai, S., Olson, C.E., Koos, R.D., 2002. Inhibition of vascular endothelial 555 growth factor/vascular permeability factor action blocks estrogen-induced uterine edema and 556 implantation in rodents. Biol Reprod 67, 1804-1810.

557 Sakurai, T., Tamura, K., Kogo, H., 2005. Stimulatory effects of eicosanoids on ovarian 558 angiogenesis in early luteal phase in cyclooxygenase-2 inhibitor-treated rats. Eur J Pharmacol $559516,158-164$.

560 Schafer-Somi, S., Sabitzer, S., Klein, D., Reinbacher, E., Kanca, H., Beceriklisoy, H.B., Aksoy, 561 O.A., Kucukaslan, I., Macun, H.C., Aslan, S., 2013. Vascular endothelial (VEGF) and epithelial 562 growth factor (EGF) as well as platelet-activating factor (PAF) and receptors are expressed in the 563 early pregnant canine uterus. Reprod Domest Anim 48, 20-26.

564 Shalaby, F., Rossant, J., Yamaguchi, T.P., Gertsenstein, M., Wu, X.F., Breitman, M.L., Schuh, 565 A.C., 1995. Failure of blood-island formation and vasculogenesis in Flk-1-deficient mice. Nature $566376,62-66$.

567 Sherer, D.M., Abulafia, O., 2001. Angiogenesis during implantation, and placental and early embryonic development. Placenta 22, 1-13. Shifren, J.L., Tseng, J.F., Zaloudek, C.J., Ryan, I.P., Meng, Y.G., Ferrara, N., Jaffe, R.B., Taylor, R.N., 1996. Ovarian steroid regulation of vascular endothelial growth factor in the human endometrium: implications for angiogenesis during the menstrual cycle and in the pathogenesis of endometriosis. J Clin Endocrinol Metab 81, 3112-3118.

Stuttfeld, E., Ballmer-Hofer, K., 2009. Structure and function of VEGF receptors. IUBMB Life 61, 915-922.

Sugino, N., Kashida, S., Karube-Harada, A., Takiguchi, S., Kato, H., 2002. Expression of vascular endothelial growth factor (VEGF) and its receptors in human endometrium throughout the menstrual cycle and in early pregnancy. Reproduction 123, 379-387. Growth FactorExpression in the Rat Uterus and Placenta throughout Pregnancy. Acta Histochem. Cytochem. 31, 419-426.

Winther, H., Ahmed, A., Dantzer, V., 1999. Immunohistochemical localization of vascular endothelial growth factor (VEGF) and its two specific receptors, Flt-1 and KDR, in the porcine placenta and non-pregnant uterus. Placenta 20, 35-43.

Yamamoto, S., Konishi, I., Tsuruta, Y., Nanbu, K., Mandai, M., Kuroda, H., Matsushita, K., Hamid, A.A., Yura, Y., Mori, T., 1997. Expression of vascular endothelial growth factor (VEGF) during folliculogenesis and corpus luteum formation in the human ovary. Gynecol Endocrinol 11, 371-381.

588 Yamashita, H., Kamada, D., Shirasuna, K., Matsui, M., Shimizu, T., Kida, K., Berisha, B., 589 Schams, D., Miyamoto, A., 2008. Effect of local neutralization of basic fibroblast growth factor or vascular endothelial growth factor by a specific antibody on the development of the corpus luteum in the cow. Mol Reprod Dev 75, 1449-1456.

592 Yi, X.J., Jiang, H.Y., Lee, K.K., O, W.S., Tang, P.L., Chow, P.H., 1999. Expression of vascular endothelial growth factor (VEGF) and its receptors during embryonic implantation in the golden hamster (Mesocricetus auratus). Cell Tissue Res 296, 339-349.

Zimmermann, R.C., Hartman, T., Bohlen, P., Sauer, M.V., Kitajewski, J., 2001. Preovulatory treatment of mice with anti-VEGF receptor 2 antibody inhibits angiogenesis in corpora lutea. Microvasc Res 62, 15-25. 


\section{Figure legends}

601 Figure 1: Expression of VEGFA, VEGFR1/FLT1 and VEGFR2/FLK1/KDR as determined by 602 Real Time (TaqMan) PCR (Xg \pm DF) in canine CL at selected stages of pregnancy (A-C). Bars 603 with different letters in (A) differ at differ at $\mathrm{P}<0.05$, and in (B) differ at $\mathrm{P}<0.001$.

605 Figure 2: Expression of VEGFA, VEGFR1/FLT1 and VEGFR2/FLK1/KDR as determined by 606 Real Time (TaqMan) PCR $(\mathrm{Xg} \pm \mathrm{DF})$ in canine pre-implantation pregnant uterus and in utero607 placental compartments (ut-pl) at selected time points of pregnancy (A-C) and during 608 antigestagen (Aglepristone ${ }^{\circledR}$ )-induced luteolysis/abortion (D-F; compared with the mid-gestation 609 group used as non-treated control). Bars with different letters differ: in (A) at $\mathrm{P}<0.001$, in (B) and 610 (E) at $\mathrm{P}<0.01$. For (C) differences are indicated underneath the graph.

611

612 Figure 3: Immunohistochemical (IHC) localization of VEGFA in the canine CL at selected time 613 points of pregnancy, i.e., pre-implantation (A), post-implantation (B), mid-gestation (C) and at 614 prepartum luteolysis (D). VEGFA expression is localized to the lutein cells (solid arrows in A615 D). There is no background staining in the isotype control (insert to D).

617 Figure 4: Immunohistochemical (IHC) localization of VEGFR1/FLT1 in the canine pregnant CL 618 at selected time points of pregnancy, i.e., pre-implantation (A), post-implantation (B), mid619 gestation (C) and prepartum luteolysis (D). VEGFR1 expression is localized to the luteal cells 620 (open arrows in A-D) and media of the blood vessels (solid arrows in A-D). There is no 621 background staining in the isotype control (insert to D). 
623 Figure 5: Immunohistochemical (IHC) localization of VEGFR2/FLK1/KDR in the canine

624 pregnant CL at selected time points of pregnancy, i.e., pre-implantation (A), post-implantation

625 (B), mid-gestation (C) and prepartum luteolysis (D). VEGFR2 expression is predominantly

626 localized to the capillary endothelial cells (open arrows in A-D), while weaker staining is

627 observed in media of some larger vessels (solid arrow in C). Luteal cells stain only weakly or

628 negatively (solid arrowheads in A-D). There is no background staining in the isotype control

629 (insert to D).

630

631 Figure 6: Immunohistochemical (IHC) localization of VEGFA in the canine pregnant uterus at 632 selected time points during pregnancy: (A,B) pre-implantation stage, (C-E) utero-placental 633 compartments (ut-pl) at mid-gestation, and in ut-pl at prepartum luteolysis (F-H). (A,B) Pre634 implantation, VEGFA is localized to the endometrial luminal (surface) epithelial cells (solid 635 arrows in A), glandular epithelial cells of the superficial and deep uterine glands (open arrows in $636 \mathrm{~A}$ and B), myometrium (open arrowheads in B) and capillary pericytes (solid arrowheads in A 637 and B). (C-E) Following placentation (representative pictures taken during mid-gestation) within 638 the ut-pl compartments, endometrial VEGFA expression is localized in the epithelial cells of the 639 superficial endometrial glands (the so-called glandular chambers) (open arrows in C) and deep 640 uterine glands (open arrows in D), media of the vessels (solid arrowhead in C) and myometrium 641 (open arrowheads in D). At prepartum luteolysis (F-G), positive uterine signals are localized in 642 the superficial (open arrows in F) and deep uterine glands (open arrows in G), vascular 643 endothelial cells (solid arrowheads in G) and myometrium (open arrowheads in G). Within the 644 placental labyrinth, signals are localized in fetal trophoblast cells (cytotrophoblast, solid 645 arrowheads in $\mathrm{E}$ and $\mathrm{H}$ ) and maternal endothelial cells (open arrows in $\mathrm{E}$ and $\mathrm{H}$ ) with distinctly 646 stronger signals observed at earlier stages of pregnancy (presented at mid-gestation, E) than 
647 during prepartum luteolysis $(\mathrm{H})$. Maternal stroma-derived decidual cells (open arrowheads in $\mathrm{H}$ )

648 display only weak staining. There is no background staining in the isotype control (insert to $\mathrm{H}$ ).

650 Figure 7: Immunohistochemical (IHC) localization of VEGFR1/FLT1 in the canine pregnant 651 uterus at selected time points during pregnancy: (A,B) pre-implantation stage, (C-E) utero652 placental compartments (ut-pl) at mid-gestation, and in ut-pl at prepartum luteolysis (F-H). (A,B) 653 pre-implantation endometrial luminal (surface) epithelial cells stain weakly for VEGFR1 (solid 654 arrows in A). Stronger endometrial signals are localized to the glandular epithelial cells of the 655 superficial and deep uterine glands (open arrows in A and B), and media of the vessels (solid 656 arrowheads in B). Myometrium stains positively (open arrowheads in B). Following implantation 657 (presented at mid-gestation in $\mathrm{C}$ and $\mathrm{D}$ ), and at prepartum-luteolysis ( $\mathrm{F}, \mathrm{G})$, similar endometrial 658 and myometrial localization patterns are observed. Signals are shown in glandular epithelial cells 659 of the superficial glands (the so-called glandular chambers; open arrows in C and F), deep uterine 660 glands (open arrows in D and G), and myocytes (open arrowheads in D and G). In the placental 661 labyrinth during mid-gestation and prepartum luteolysis, cytotrophoblast cells (solid arrowheads 662 in $\mathrm{E}$ and $\mathrm{H}$ ) are stained, with distinctly stronger signals at earlier stages of pregnancy (represented 663 at mid-gestation in E). Maternal endothelial cells are indicated with open arrows in $\mathrm{E}$ and $\mathrm{H}$.

664 Maternal stroma-derived decidual cells display only weak staining (open arrowheads in E and H).

665 There is no background staining in the isotype control (insert to $\mathrm{H}$ ).

666

667 Figure 8 Immunohistochemical (IHC) localization of VEGFR2/FLK1/KDR in the canine 668 pregnant uterus at selected time points during pregnancy: $(\mathrm{A}, \mathrm{B})$ pre-implantation stage, $(\mathrm{C}-\mathrm{E})$ 669 utero-placental compartments (ut-pl) at mid-gestation, and in ut-pl at prepartum luteolysis (F-H). 670 (A,B ) Pre-implantation endometrial luminal (surface) epithelial cells (solid arrows in A), 
671 capillary pericytes (solid arrowheads in A and B) and myometrial myocytes (open arrowheads in

672 B) are stained strongly for VEGFR2. Weaker endometrial signals are localized to the glandular 673 epithelial cells of the superficial and deep uterine glands (open arrows in A and B). Following 674 implantation (presented at mid-gestation; C-E), strong endometrial signals are localized in the 675 epithelium of superficial glands (the so-called glandular chambers, open arrows in C), capillary 676 pericytes (solid arrowheads in C and D) and vascular endothelial cells (solid arrow in D). Deep 677 uterine glands (open arrows in D) are stained weakly for VEGFR2. In myometrium, signals are 678 localized in myocytes (open arrowheads in D). At prepartum luteolysis, similar endometrial and 679 myometrial localization patterns are observed ( $F$ and $G$ ). Signals are localized to the glandular 680 epithelial cells of glandular chambers (open arrows in F) and deep uterine glands (open arrows in $681 \mathrm{G}$ ), capillary pericytes (solid arrowheads in F) and myocytes (open arrowheads in G). In the 682 placental labyrinth (presented at mid-gestation) trophoblast cells (cytotrophoblast, solid 683 arrowheads in E), capillary pericytes (solid arrows in E), and maternal endothelial cells (open 684 arrow in E), are predominantly stained. During prepartum luteolysis, strong staining is localized 685 in maternal endothelial cells (open arrow in H). Positively stained cytotrophoblast is indicated 686 with solid arrowheads in H. Only weak staining is observed in maternal decidual cells throughout 687 gestation (open arrowheads in $\mathrm{H}$ ) and syncytiotrophoblast (solid arrows in $\mathrm{H}$ ). There is no 688 background staining in the isotype control (insert to $\mathrm{H}$ ).

\section{Table1}

691 List of primers and TaqMan Probes used for the semi-quantitative RT-PCR 

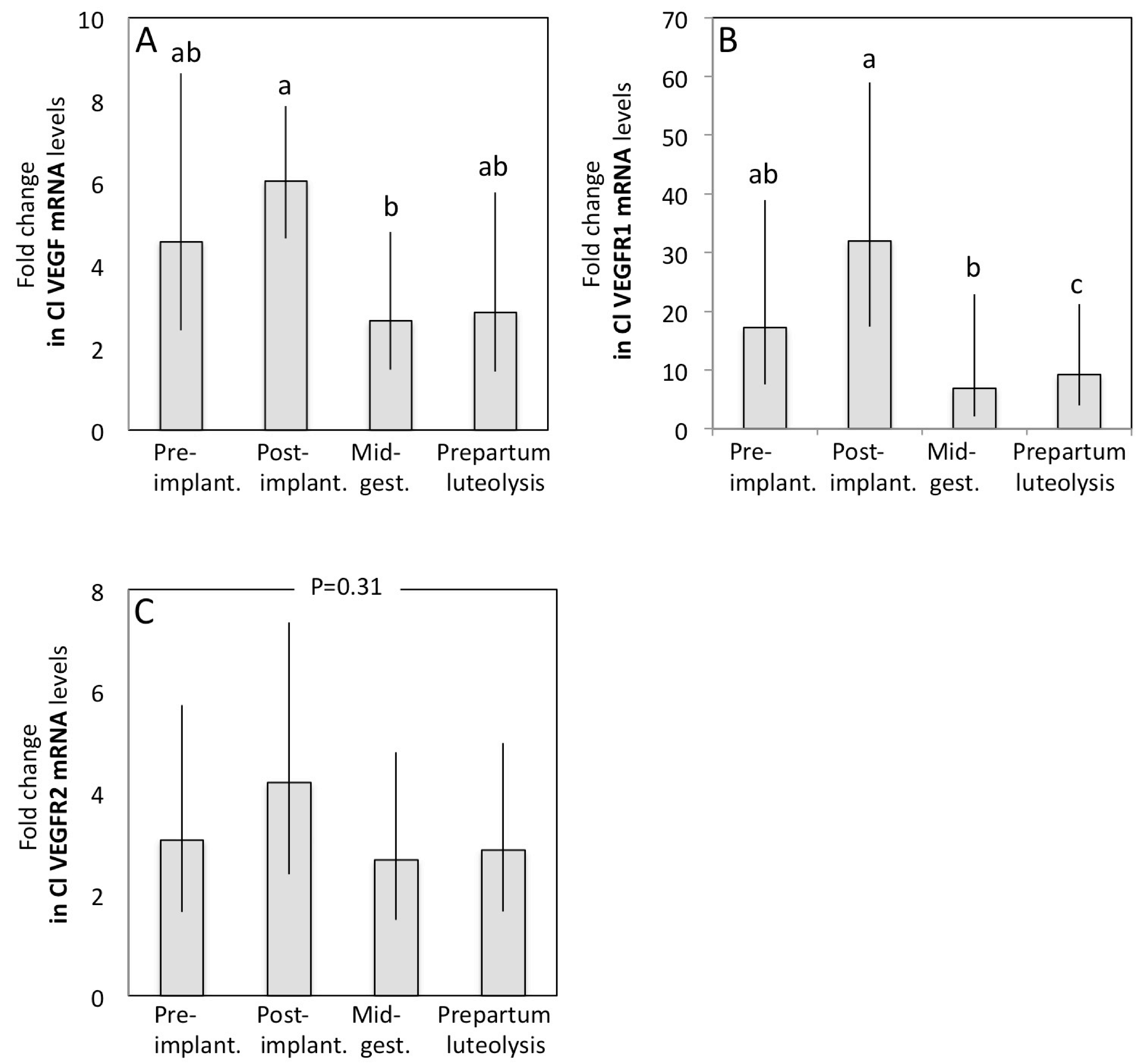

Figure 1 


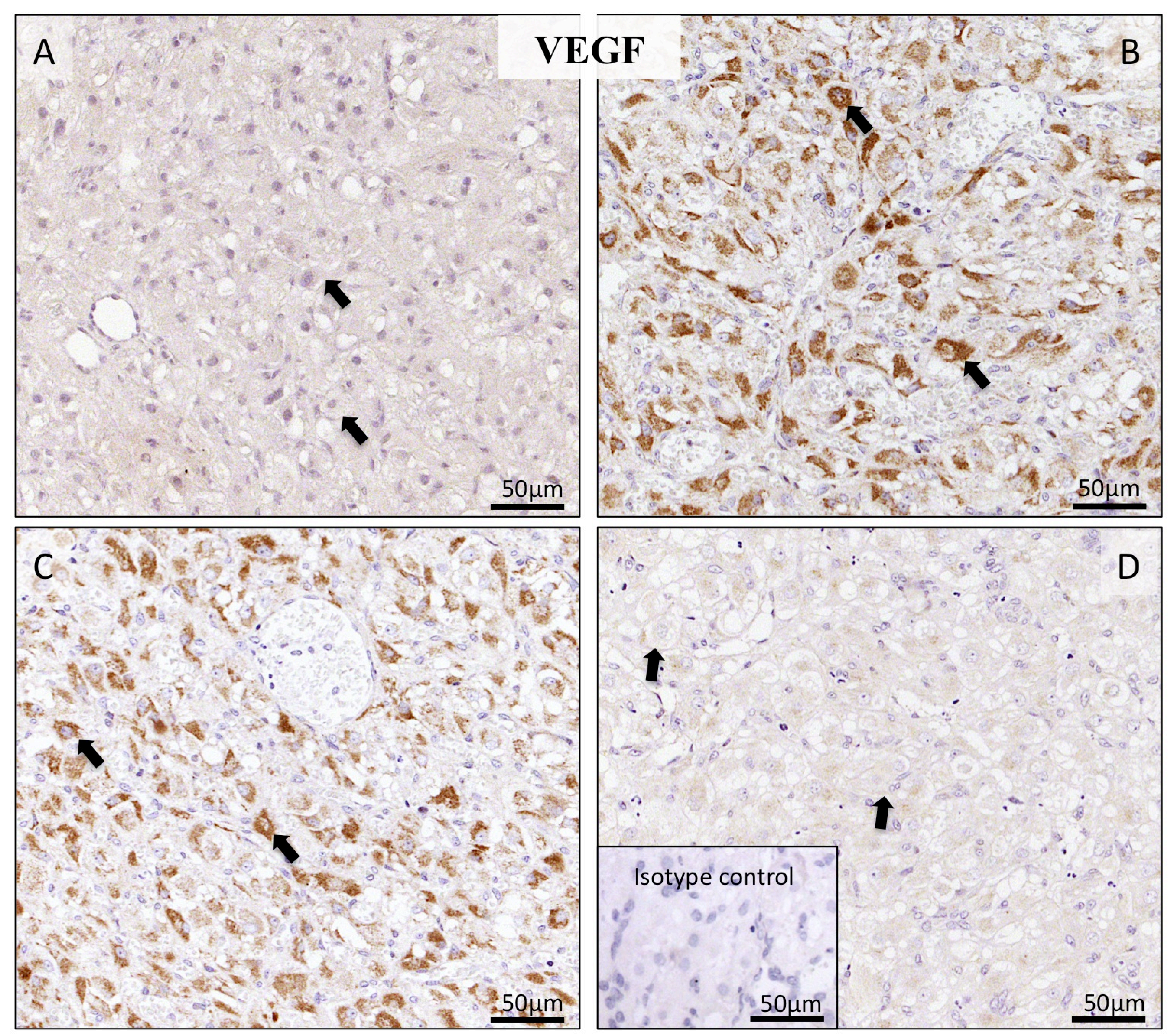

Figure 3 


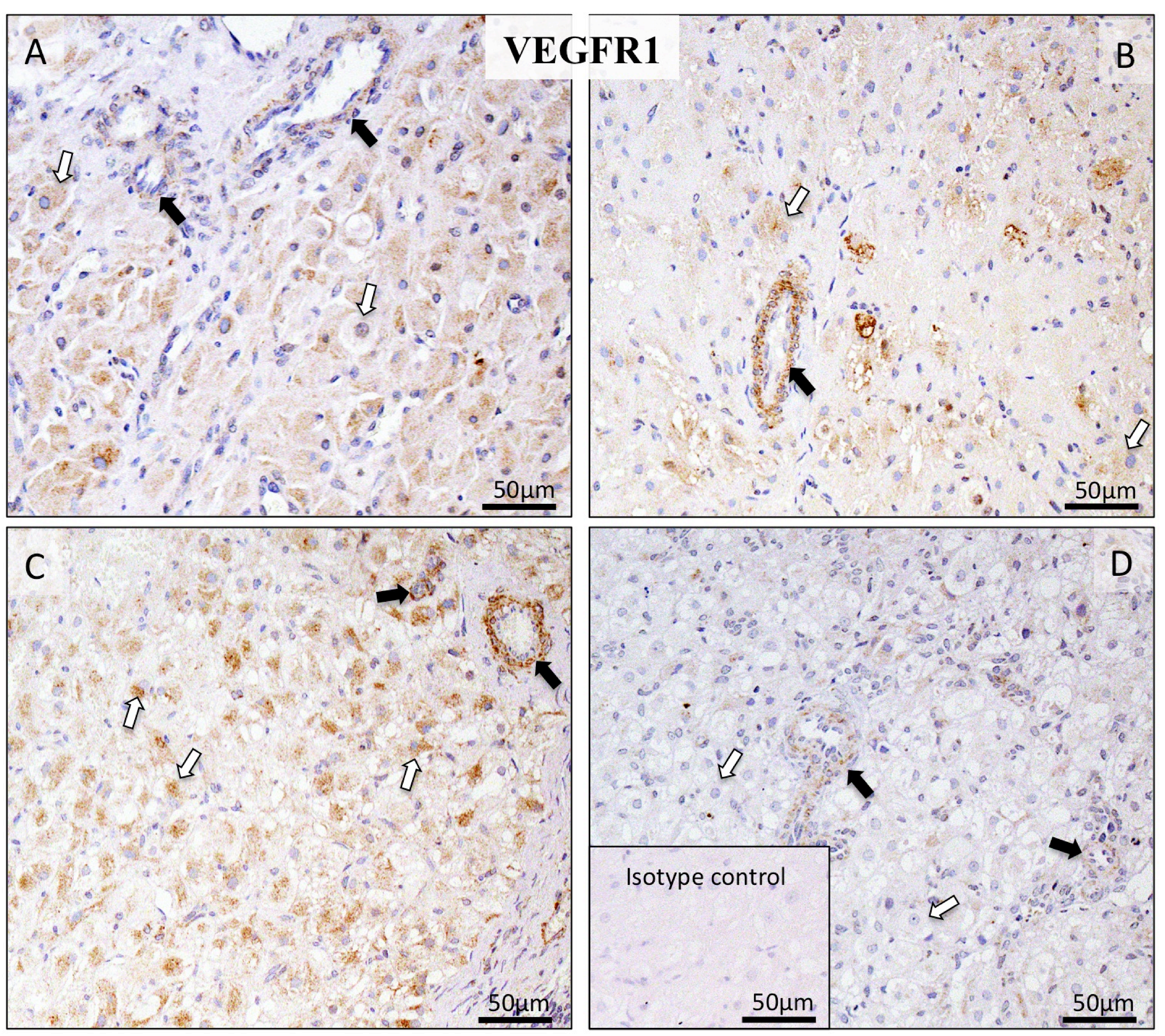

Figure 4 


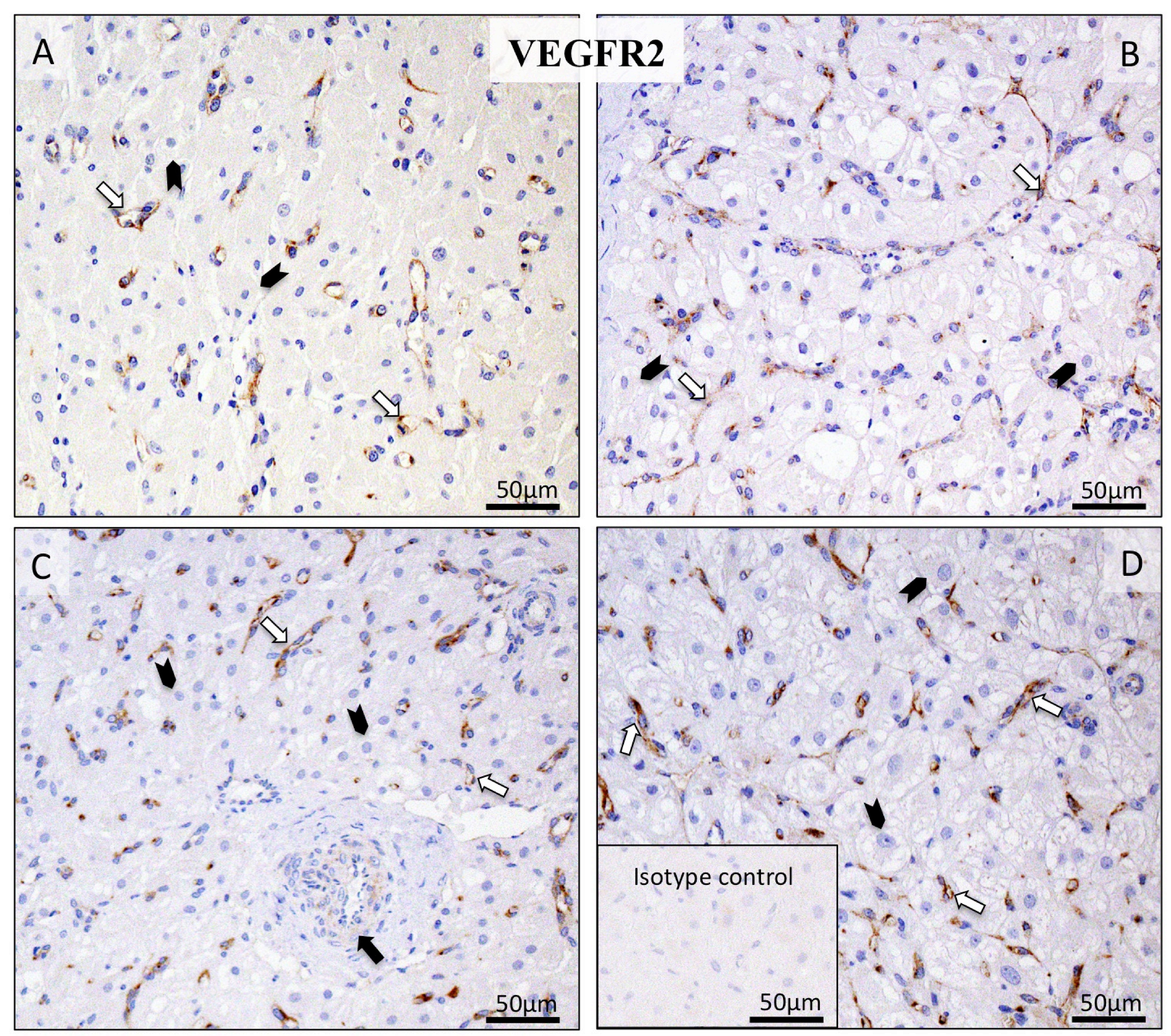

Figure 5 




Figure 6 




Figure 7 


\begin{tabular}{|l|l|l|l|}
\hline GAPDH & AB028142 & $\begin{array}{l}\text { Forward: 5'-GCT GCC AAA TAT GAC GAC ATC A-3' } \\
\text { Reverse: 5'-GTA GCC CAG GAT GCC TTT GAG-3' } \\
\text { TaqMan probe: 5'-TCC CTC CGA TGC CTG CTT CAC TAC CTT-3' }\end{array}$ & $75 \mathrm{bp}$ \\
\hline 18SrRNA & FJ797658 & $\begin{array}{l}\text { Forward: 5'-GTC GCT CGC TCC TCT CCT ACT-3' } \\
\text { Reverse: 5'-GGC TGA CCG GGT TGG TTT-3' } \\
\text { TaqMan probe: 5'-ACA TGC CGA CGG GCG CTG AC-3' }\end{array}$ & $125 \mathrm{bp}$ \\
\hline VEGFA & NM001003175 & $\begin{array}{l}\text { Forward: 5'-GTG CCC ACT GAG GAG TTC AAC-3' } \\
\text { Reverse: 5'-CCC TAT GTG CTG GCC TTG AT-3' } \\
\text { TaqMan probe: 5'-CAC CAT GCA GAT TAT GCG GAT CAA ACC-3' }\end{array}$ & $72 \mathrm{bp}$ \\
\hline VEGFR1 & AF262963 & $\begin{array}{l}\text { Forward: 5'-TGC CTG AAA CAG TGA GAA AGG A-3' } \\
\text { Reverse: 5'-TGC AGA ACT GTT TGC CAT TCC-3' } \\
\text { TaqMan probe: 5'-AAA GGC TGA GCA TTA CTA AAT CTG CCT-3' }\end{array}$ & $81 \mathrm{bp}$ \\
\hline VEGFR2 & $\begin{array}{l}\text { DQ269018/ } \\
\text { NM001048024 }\end{array}$ & $\begin{array}{l}\text { Forward: 5'-TGA CAT GGC CTC GGT CAT T-3' } \\
\text { Reverse: 5'-TGT TGG TCG CTA ACA GAA GCA-3' } \\
\text { TaqMan probe: 5'-CTA CGT TCA AGA TTA CAG GTC TCC ATT-3' }\end{array}$ & $75 \mathrm{bp}$ \\
\hline
\end{tabular}

